\title{
Analysis of polypyrrole-coated stainless steel electrodes - Estimation of specific capacitances and construction of equivalent circuits
}

\author{
R RAMYA and M V SANGARANARAYANAN* \\ Department of Chemistry, Indian Institute of Technology Madras, Chennai 600036 \\ e-mail: sangara@iitm.ac.in
}

\begin{abstract}
The galvanostatic polymerization of pyrrole is carried out on stainless steel electrodes using $p$-toluene sulphonic acid. The morphology of the film is studied from Scanning Electron Microscopy (SEM) measurements while the nature of the substrate is analysed using Energy Dispersive X-ray Spectroscopy (EDAX) technique. The electrochemical behaviour is studied using cyclic voltammetry, chargedischarge analysis and impedance spectroscopy. The feasibility of the electrode for supercapacitor applications is investigated. The specific capacitance is estimated as $\sim 10^{2}$ Farads per gram with $10^{3}$ chargedischarge cycles. A plausible equivalent circuit for the system is proposed and the circuit parameters are obtained by non-linear regression analysis.
\end{abstract}

Keywords. Polypyrrole; equivalent circuit; impedance spectroscopy; specific capacitance; chargedischarge; supercapacitors.

\section{Introduction}

The development of electrochemical supercapacitors occupies a pivotal role in the context of electrochemical energy storage and conversion devices. ${ }^{1}$ The major advantages as envisaged for the electrochemical supercapacitors are as follows: ${ }^{2}$ (i) rapid rates of charge-discharge rate, (ii) high power densities, (iii) large cycle life and (iv) ease of fabrication. There exist three main classes of electrochemical supercapacitors viz. oxide based, ${ }^{3-5}$ carbon nanotubes $^{6-8}$ and conducting polymers ${ }^{9}$ based. The feasibility of Under Potential Deposition (UPD) systems as suitable candidates is also being pursued. ${ }^{10}$ Each of these systems has distinct advantages and limitations.

The conducting polymers based systems provide long-term stability and yield large number of chargedischarge cycles. $\left(\sim 10^{6}\right)$ in energy storage devices. Among a variety of polymers studied extensively in energy storage and conversion devices, mention may be made of polyacetylene, ${ }^{11}$ polyaniline, ${ }^{12}$ polythiophene, ${ }^{13}$ polyindole, ${ }^{14}$ polypyrrole ${ }^{15}$ polyphenelyne ${ }^{16}$, etc. The polypyrrole-based systems are stable under different environmental conditions and are employed in sensors ${ }^{17}$ and actuators. ${ }^{18}$ The objectives of this Communication are (i) to prepare polypyrrole coated stainless steel electrodes using $p$-toluene sul-

\footnotetext{
*For correspondence
}

phonic acid as dopant; (ii) to analyse the performance of the electrodes as supercapacitors using cyclic voltammetry, galvanostatic charge-discharge and impedance spectroscopy; (iii) to characterize the electrodes using SEM and EDAX measurements and (iv) to propose a plausible equivalent circuit model and reproduce theoretically Nyquist and Bode plots using non-linear regression analysis.

\section{Experimental}

\subsection{Electrodes}

Stainless steel (SS) foils commercially available were cut into electrodes of $1 \mathrm{~cm}^{2}$ area and $1 \mathrm{~mm}$ thickness. SS foil was polished with emery paper to a smooth finish, and ultrasonicated before use. These were employed as working electrodes. Platinum wire (Bioanalytical systems, USA) was used as the counter electrode while $\mathrm{Ag} / \mathrm{AgCl}$ (Bioanalytical systems, USA) served as the reference electrode. The temperature was maintained at $24 \pm 1{ }^{\circ} \mathrm{C}$.

\subsection{Chemicals}

Pyrrole (Sigma Aldrich) was distilled under reduced pressure and stored at $4^{\circ} \mathrm{C}$ in an inert atmosphere; $p$ toluenesulphonic acid (Thomas Baker, India) was used as received. 


\subsection{Electrochemical measurements}

Cyclic voltammetry, Galvanostatic charge/discharge experiments and impedance analysis were done using the electrochemical workstation $\mathrm{CHI}$ 660B $(\mathrm{CH}$ Instruments, USA). Impedance measurements were carried out using $5 \mathrm{mV}$ as the excitation signal with a frequency range of $10^{5}$ to $10^{-2} \mathrm{~Hz}$.

\subsection{Characterization studies}

FTIR spectra was recorded using a Perkin-Elmer spectrophotometer while SEM images and EDAX spectra were taken using Philips FEI Quanta 200.

\section{Results and discussion}

\subsection{Polymerization}

3.1a Galvanostatic polymerization: Figure 1 depicts the galvanostatic polymerization of pyrrole on the stainless steel substrate in the presence of $0.5 \mathrm{M}$ PTS, which was carried out using a current density of $8 \mathrm{~mA} / \mathrm{cm}^{2}$ for $60 \mathrm{~s}$. Figure 1 depicts the resulting chronopotentiogram and a mass loading of $0.166 \mathrm{mg} /$ $\mathrm{cm}^{2}$ (assuming the faradaic efficiency to be unity) was estimated. Since the polymerization occurs at $\sim 0.75 \mathrm{~V}$, a flat region is observed beyond this potential.

3.1b FT-IR measurements: The chemical nature of the PTS doped Ppy grown on SS is ascertained using

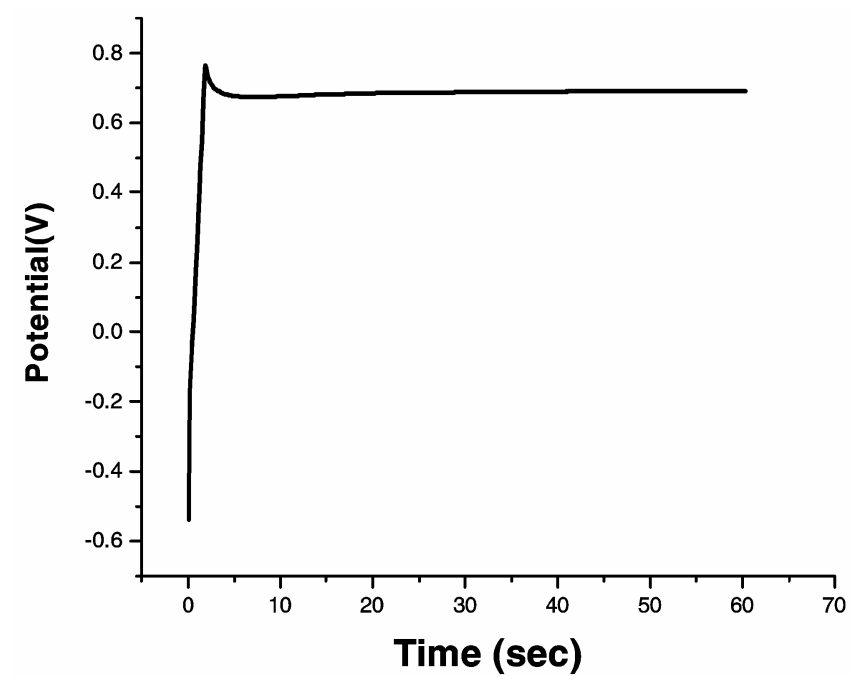

Figure 1. Chronopotentiogram depicting the electropolymerization of pyrrole on SS using $0.01 \mathrm{M}$ pyrrole in presence of $0.5 \mathrm{M} p$-toluenesulphonic acid. the FTIR measurements as shown in figure 2. The customary peaks ${ }^{19}$ appearing at 1539, 1457, 1297, 1040,1178 and $889 \mathrm{~cm}^{-1}$ are assigned due to the vibrations of 2-5 di-substituted polypyrrole, $\mathrm{CH}$ inplane vibrations, $\mathrm{N}-\mathrm{C}$ stretching vibrations and $\mathrm{CH}$ out of plane vibration.

3.1c SEM Measurements and energy dispersive $X$-ray spectroscopy: The SEM measurements enable ascertaining the morphology of the electropolymerized Ppy; the actual pattern depends upon the experimental polymerization conditions such as current density, time of polymerization and applied potential. Figure 3a depicts a typical SEM of the Ppy-coated SS electrode wherein the particle size is estimated as $0.5 \mu \mathrm{m}$. It is seen that a spear-shaped morphology having large pore size has resulted; this indicates satisfactory electronic and ionic conductivities. EDAX studies also provide information regarding the nature of the substrate obtained after polymerization. Figure $3 \mathrm{~b}$ indicates that the essential peaks anticipated for SS substrates are noticed.

\subsection{Characterization of Ppy coated SS}

In order to test the feasibility of the polypyrrole coated SS electrodes, electrochemical studies were performed. For this purpose, the Ppy-coated SS electrodes were immersed in PTS solution in a threeelectrode arrangement.

3.2a Cyclic voltammetric studies: Figure 4 depicts the cyclic voltammogram of SS/Ppy/PTS electrode performed at various scan rates. A pseudocapacitive current is observed with increase in scan rate. This behaviour in turn yields large specific capacitances. The pseudocapacitance is calculated from ${ }^{10}$

$$
C_{c v}=\Delta q / \Delta V \times m
$$

where the charge $\Delta q$ is obtained by integrating the current for a chosen scan rate pertaining to either cathodic or anodic current and $\Delta V$ denotes the potential range, $\mathrm{m}$ being the mass of Ppy.

3.2b Charge-discharge studies: In order to ascertain the feasibility of SS/Ppy/PTS electrode for supercapacitor applications, galvanostatic charge-discharge cycles were performed for various potential ranges. Figure 5 depicts two typical charge-discharge curves with current densities of $0.8 \mathrm{~mA} / \mathrm{cm}^{2}$, and $5.0 \mathrm{~mA} / \mathrm{cm}^{2}$. 


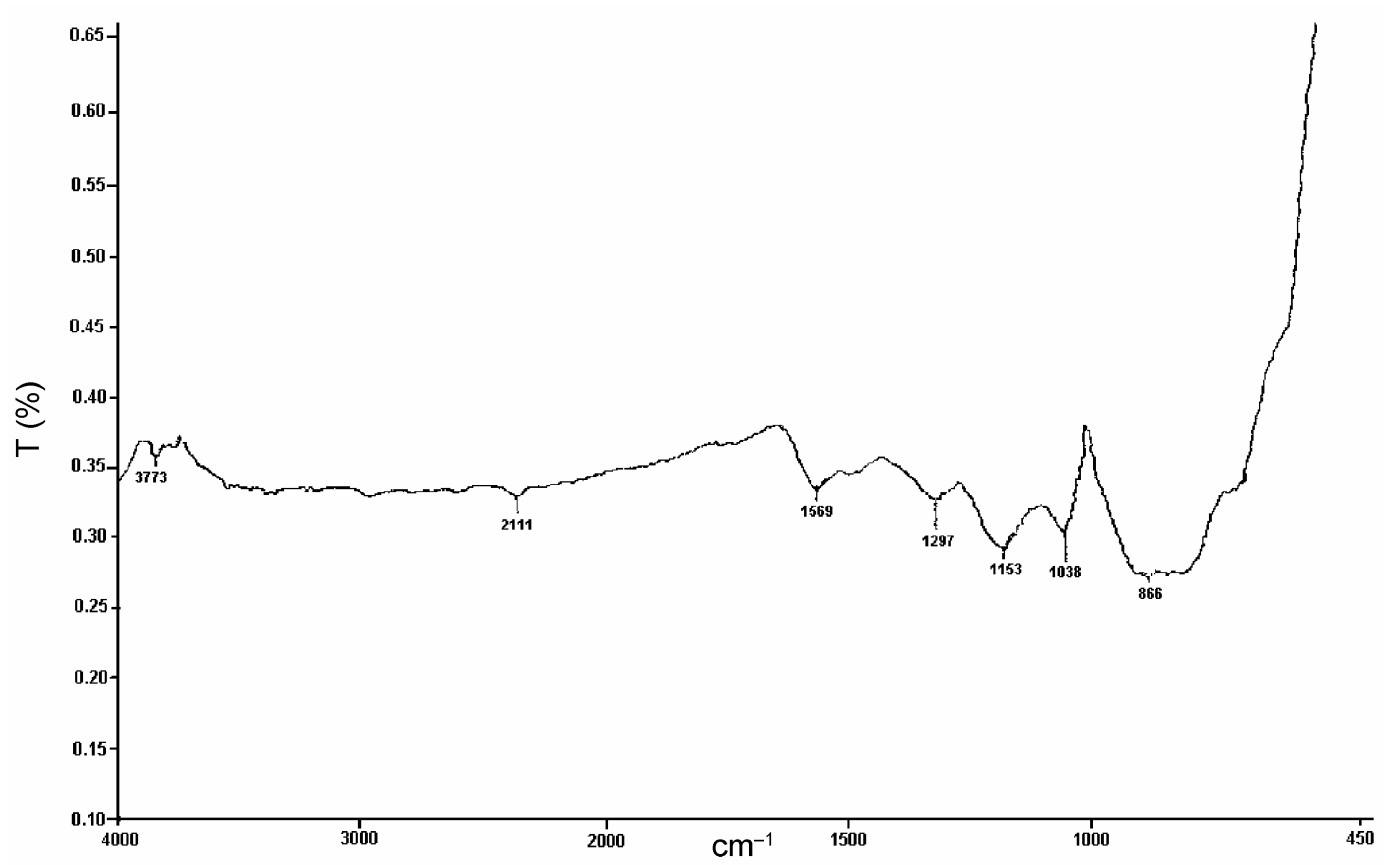

Figure 2. FTIR spectra of polypyrrole coated SS electrode.
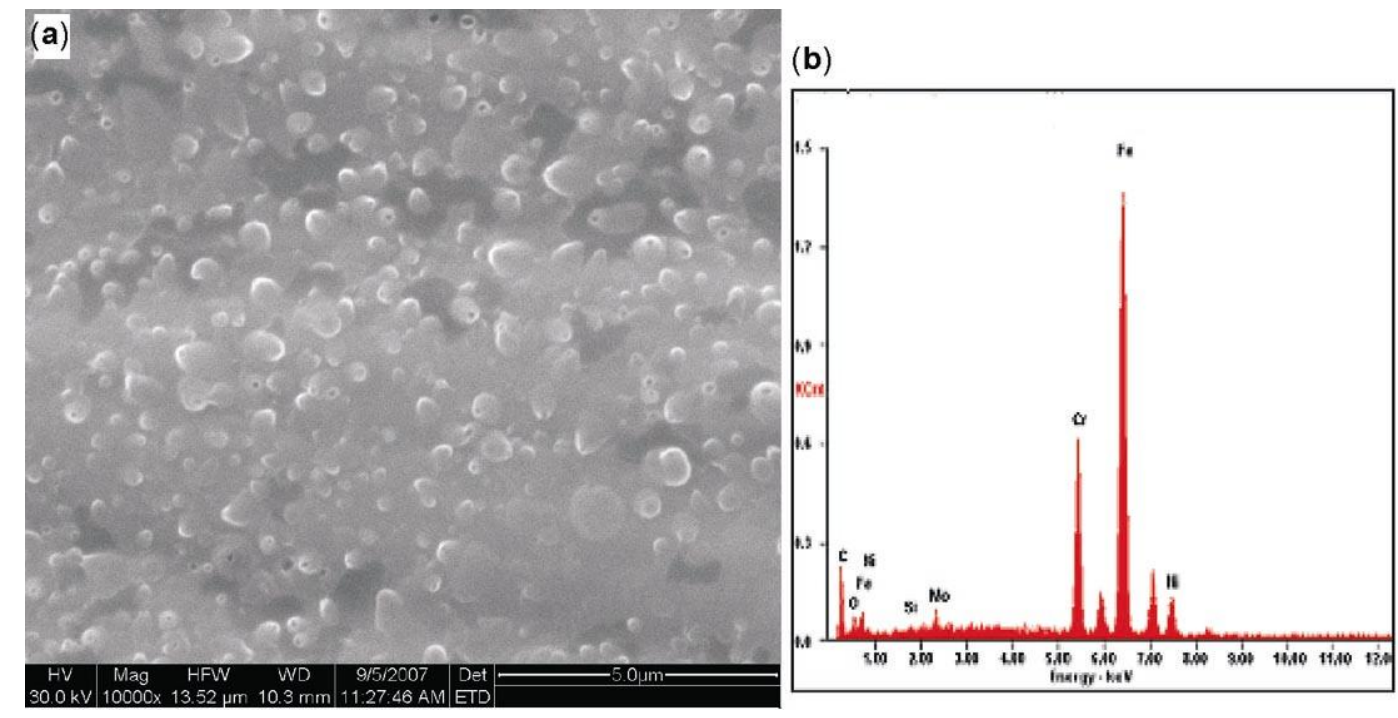

Figure 3. (a) Scanning Electron Micrograph of Ppy on SS at 10000 times magnification, (b) EDAX spectrum pertaining to Ppy coated SS.

The linearity of the charge-discharge curves indicates the feasibility of the electrode material for design of supercapacitors. The specific capacitance is estimated from ${ }^{20}$

$$
C_{c p}=I \times \Delta t / \Delta V \times m,
$$

where $i, \Delta t, \Delta V$ and $m$ denote current density, discharge time, potential range and the active weight of the electrode material respectively. The specific capacitances (in $\mathrm{F} / \mathrm{g}$ ) at 0.8 and $5.0 \mathrm{~mA} / \mathrm{cm}^{2}$ respectively are estimated as 200.0 and $96.0 \mathrm{~F} / \mathrm{g}$. The variation of specific capacitance with the number of cycles is shown in figure 6 which depicts slight changes in the magnitude with the number of cycles. However, a two-electrode construction is required in order to ascertain the exact cycle-life. 
Table 1. Equivalent circuit parameters deduced by fitting the Nyquist and Bode plots to the circuit of figure 9 . The solution resistance $\left(R_{s}\right)$ is $1.85 \mathrm{ohms} \mathrm{cm}$.

\begin{tabular}{lccccc}
\hline $\begin{array}{l}\text { Potential } \\
(v)\end{array}$ & $\begin{array}{c}R_{c t} \\
(\mathrm{ohm} \mathrm{cm})\end{array}$ & $\begin{array}{c}\mathrm{CPE}_{1} \\
\left(10^{-3} \mathrm{ohm}^{-1} \mathrm{~cm}^{-2} \mathrm{~s}\right)\end{array}$ & $n_{1}$ & $\begin{array}{c}W \\
\left(\mathrm{ohm} \mathrm{cm}^{2} \mathrm{~s}^{-1 / 2}\right)\end{array}$ & $\begin{array}{c}C_{d l} \\
\left(\mathrm{in}^{2} 0^{-2} \text { Farad cm }^{-2}\right)\end{array}$ \\
\hline 0.2 & 0.91 & 0.60 & 0.83 & 0.060 & 0.60 \\
0.3 & 1.50 & 0.70 & 0.77 & 0.050 & 0.65 \\
0.4 & 1.90 & 0.67 & 0.77 & 0.031 & 0.70 \\
0.5 & 1.92 & 0.82 & 0.76 & 0.028 & 0.75 \\
\hline
\end{tabular}

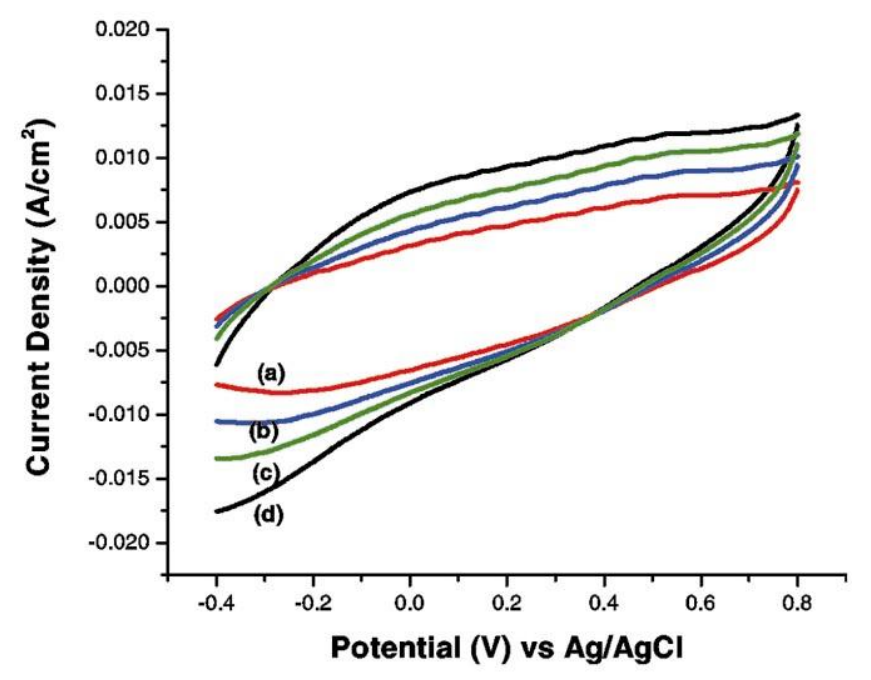

Figure 4. Cyclic Voltammogram for SS/Ppy/PTS electrode at various scan rates: (a) $200 \mathrm{mVs}^{-1}$; (b) $300 \mathrm{mVs}^{-1}$; (c) $400 \mathrm{mVs}^{-1}$ and (d) $500 \mathrm{mVs}^{-1}$. The potential is scanned from $-0.4 \mathrm{~V}$ to $0.8 \mathrm{~V}$.

3.2c Impedance spectroscopy: There are various methods of representing electrochemical impedance data and among these, the most widely employed as regards the analysis of supercapacitors are (i) $\mathrm{Ny}$ quist plots and (ii) Bode plots (figure 7). If our objective is to obtain the specific capacitances alone, a plot of $-Z^{\prime \prime}$ vs $1 / f$ yields $C_{t}$ from the slope of the plot viz $d\left(-Z^{\prime \prime}\right) / d(1 / f)$ wherefrom the specific capacitance is deduced viz.

$$
C_{t}=1 / 2 \times \pi \times m \times d\left(-Z^{\prime \prime}\right) / d(1 / f),
$$

where $C_{t}$ denotes the specific capacitance from impedance spectra and $-Z^{\prime \prime}$ is the imaginary part of impedance, $f$ being the frequency (figure 8 ).

On the other hand, if our objective is to estimate all the system parameters, it is essential to construct equivalent circuits and employ a non-linear least squares fitting. This will necessitate the formulation of real and imaginary parts of impedances as well as the appropriate phase angles. An alternate simpler strategy is to employ the commercial in-built soft-
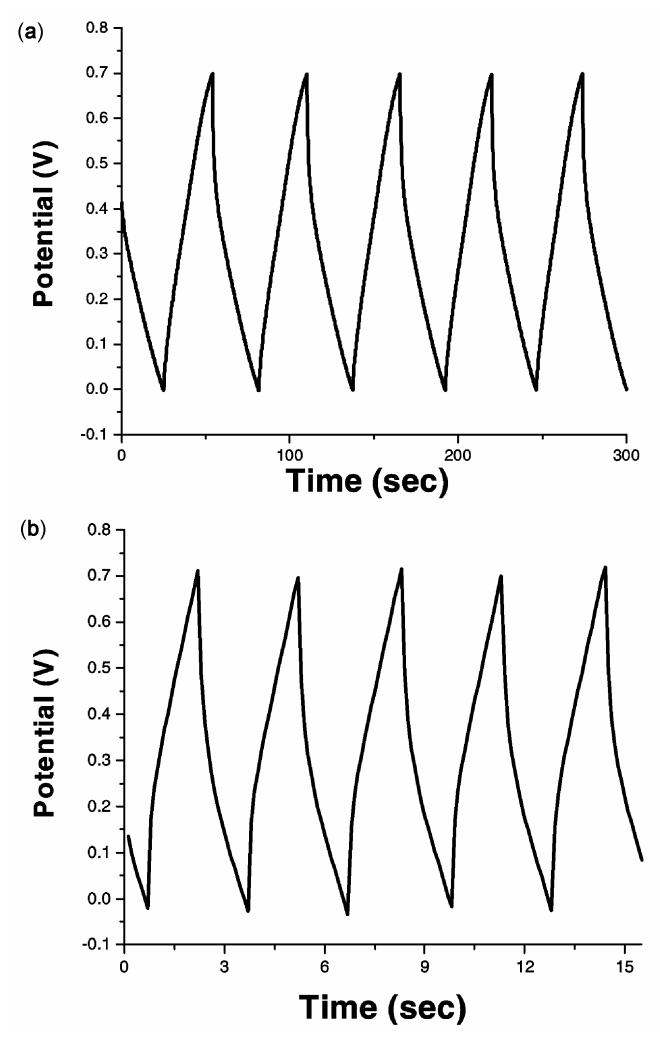

Figure 5. Galvanostatic charge-discharge curves of $\mathrm{SS} / \mathrm{Ppy} / \mathrm{PTS}$ electrode at current densities of (a) $0.8 \mathrm{~mA} /$ $\mathrm{cm}^{2}$ and (b) $5.0 \mathrm{~mA} / \mathrm{cm}^{2}$.

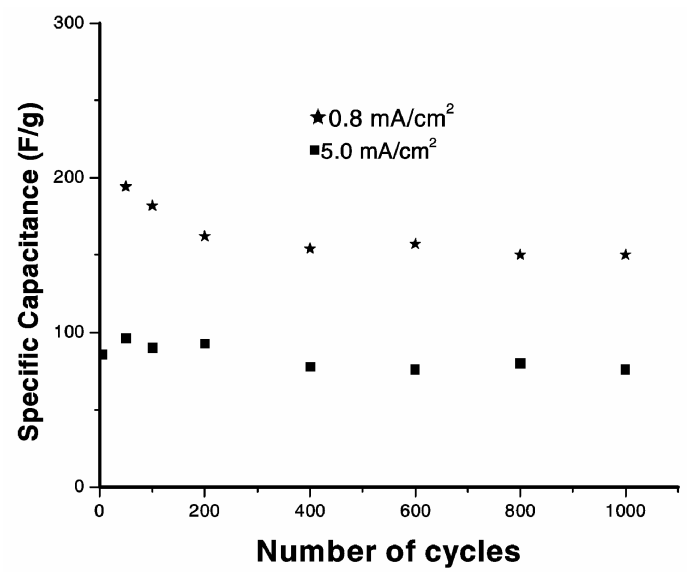

Figure 6. The dependence of specific capacitance on the number charge-discharge cycles. 

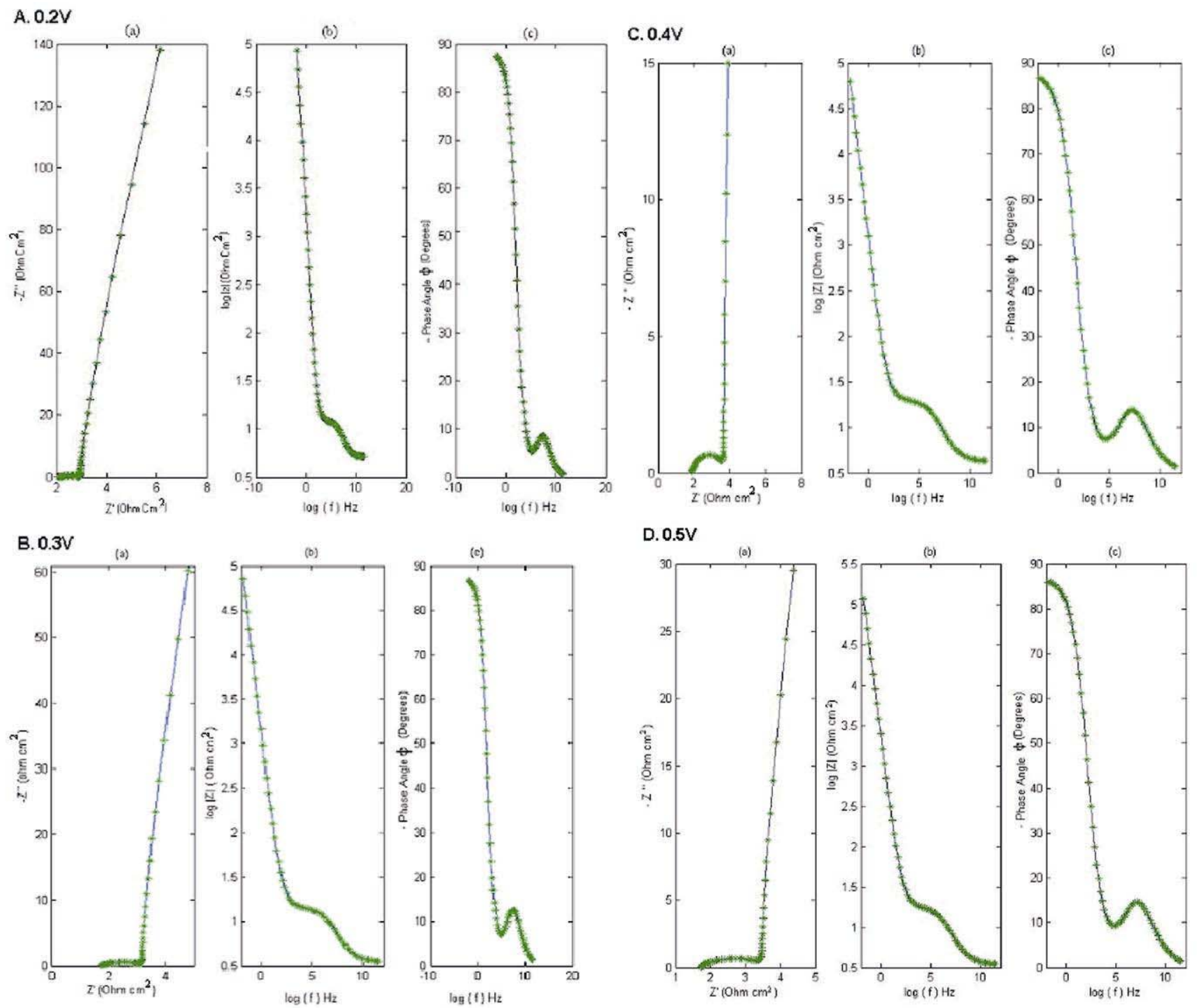

Figure 7. Impedance spectrum of SS/Ppy/PTS depicting the Nyquist and Bode plots in the frequency range $10^{5} \mathrm{~Hz}$ to $10^{-2} \mathrm{~Hz}$ at various potentials (A) $0.2 \mathrm{~V}$ (B) $0.3 \mathrm{~V}$ (C) $0.4 \mathrm{~V}$ and (D) $0.5 \mathrm{~V}$. (a) Nyquist (b) Bode-(log $|Z|$ vs frequency) and (c) Bode-(phase angle vs frequency) plots. The points denote the experimental data while the line represents the fitting obtained using the equivalent circuit of figure 9 in MATLAB.

Table 2. The specific capacitances of Ppy coated SS electrode obtained* from different methods.

\begin{tabular}{lll}
\hline Method & \multicolumn{1}{c}{ Formula } & \multicolumn{1}{c}{$\begin{array}{c}\text { specific capacitance } \\
\left.\text { (in } 10^{2} \mathrm{~F} / \mathrm{g}\right)\end{array}$} \\
\hline Cyclic voltammetry & $C_{c v}=\Delta q / \Delta V \times m$ & $1.20(0.2 \mathrm{~V})$ \\
& & $1.08(0.3 \mathrm{~V})$ \\
& & $0.97(0.4 \mathrm{~V})$ \\
Galvanostatic charge-discharge & $C_{c p}=i \times \Delta t / \Delta V \times m$ & $0.92(0.5 \mathrm{~V})$ \\
& & $2.00\left(0.8 \mathrm{~mA} / \mathrm{cm}^{2}\right)$ \\
Impedance spectroscopy & $C_{t}=1 / 2 \times \pi \times m \times d\left(-Z^{\prime \prime}\right) / d(1 / f)$ & $0.96\left(5.0 \mathrm{~mA} / \mathrm{cm}^{2}\right)$ \\
& & $0.63(0.2 \mathrm{~V})$ \\
& & $0.67(0.3 \mathrm{~V})$ \\
& & $0.74(0.4 \mathrm{~V})$ \\
& & $1.02(0.5 \mathrm{~V})$ \\
\hline
\end{tabular}

*The experimental specific capacitances involve in each case, numerical analysis of the corresponding response and consequently, the estimated values are expected to involve an error of ca. $3 \%$ 
ware packages of the electrochemical workstations to derive the circuit parameters after assuming an equivalent circuit a priori. Consequently, it is not uncommon to postulate various types of equivalent circuits for a given situation; however, it is imperative that the equivalent circuit postulated yields the fitting of the experimental data whatever be the representation viz. (Nyquist or Bode plots or phase angle vs frequency behaviour). Further, there may be several equivalent circuits for a given set of data; it turns out that the Bode plots are sensitive to small variations in system parameters in contrast to $\mathrm{Ny}$ quist plots. Several equivalent circuits were tried to

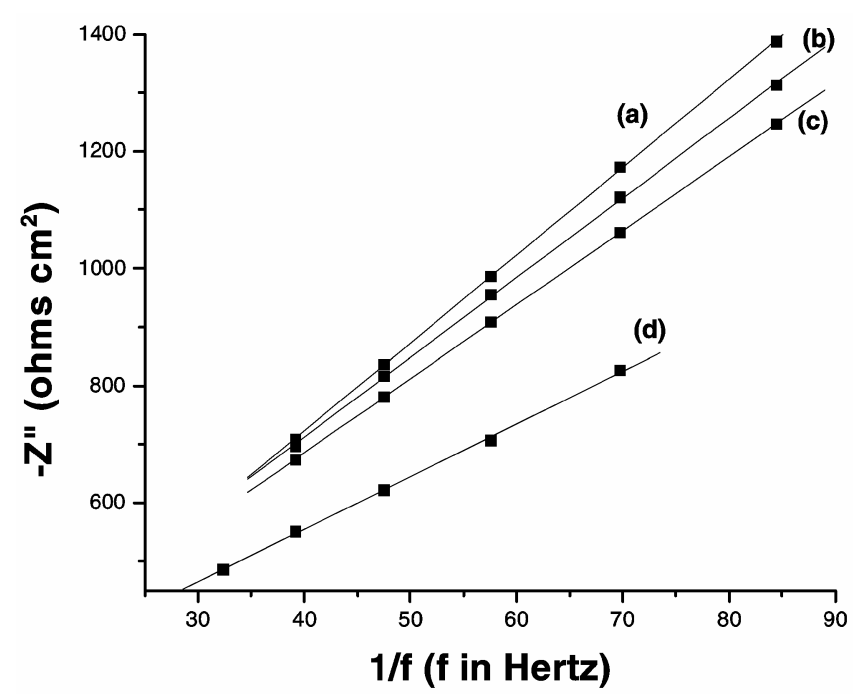

Figure 8. The variation of the imaginary component of impedance $\left(-Z^{\prime \prime}\right)$ with reciprocal of the frequency $(1 / f)$ at applied potentials of (a) $0.2 \mathrm{~V}$ (b) $0.3 \mathrm{~V}$ (c) $0.4 \mathrm{~V}$ and (d) $0 \cdot 5 \mathrm{~V}$. The points denote the experimental data while the line is obtained from the linear regression analysis. The correlation coefficients for (a), (b), (c) and (d) are respectively $0.99,0.99,0.99$ and 0.98 .

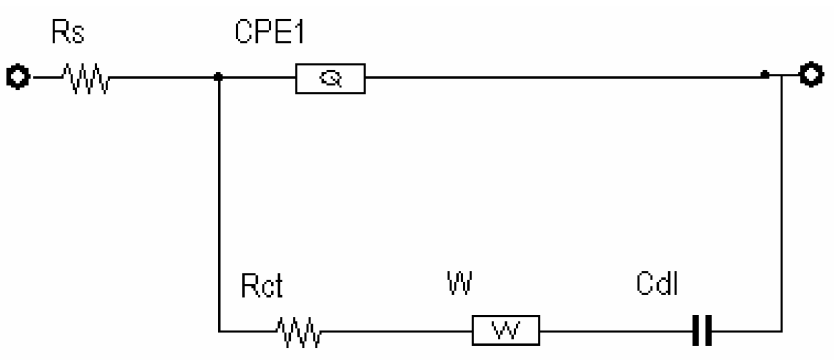

Figure 9. Equivalent circuit for PTS doped Ppy electrode. $R_{s}$, solution resistance, $R_{c t}$, charge transfer resistance, CPE1, constant phase element, W, Warburg impedance and $C_{d l}$, double layer capacitance. reproduce the Bode and Nyquist plots and the equivalent circuit shown in figure 9 was found to fit the experimental impedance data. The governing equations are shown in Appendix A. In this model, $C_{d l}$ represents the double layer capacitance and $W$ is the Warburg impedance associated with the semiinfinite linear diffusion. The constant phase element CPE1 incorporates the inhomogeneous nature of the electrode surface as well as diffusion of ions at the interface. The constant phase elements in fact include effects ${ }^{22}$ due to factors such as the porosity, inhomogenities at electrode/electrolyte interface, roughness of the electrode and dynamic disorder related with diffusion. Since the best set of parameters arise from the built-in function of MATLAB, these estimates do not have error-bars. In the analysis of insertion-de-insertion of lithium ions into polydioxythiophene, an analogous equivalent circuit has been postulated ${ }^{21}$.

Table 2 provides the circuit parameters obtained from the non-linear regression analysis using MATLAB 6.5 version.

\subsection{Estimation of specific capacitance}

In table 2, the calculation of specific capacitances using the three electrochemical techniques is indicated. It is anticipated that the three methods will not yield identical estimates on account of different parameters measured in each case. Nevertheless, values deduced using galvanostatic charge-discharge experiments have more significance in view of their usefulness in fabrication of devices. On the other hand, impedance spectroscopy ${ }^{23}$ has the advantage of yielding not only specific capacitances but also other system parameters such as double layer capacitances, charge transfer, ohmic and diffusional resistances.

It is imperative to point out that for designing different types of electrochemical supercapacitors, twoelectrode constructions are required which provide accurate estimates of the specific capacitance under practical discharge conditions.

\section{Conclusions}

The specific capacitance of Ppy-coated SS electrodes is estimated as $\sim 10^{2} \mathrm{~F} / \mathrm{g}$ using three different electrochemical techniques. The particle size is ca. $500 \mathrm{~nm}$ as deduced from SEM measurements. A plausible equivalent circuit is formulated which pro- 
vides a complete fitting of the electrochemical impedance data and the circuit parameters are deduced using non-linear regression analysis carried out with MATLAB

\section{Appendix A}

In this Appendix, the expressions for various components of the impedance are derived. For the equivalent circuit depicted in figure 9, the total impedance is represented as

$$
Z_{t}=R_{s}+Z_{1} \| Z_{2}
$$

where $R_{s}$ denotes the solution resistance, $Z_{1}$ and $Z_{2}$ being the impedances given as

$$
\begin{aligned}
& Z_{1}=\frac{1}{Y(j w)^{n_{1}}} \\
& Z_{2}=R_{c t}+W+\frac{1}{j w C_{d l}}
\end{aligned}
$$

Employing equations (A2) and (A3), equation (A1) becomes

$$
Z_{t}=R_{s}+\left[\frac{Y^{-1}(j w)^{-n_{1}}\left(R_{c t}+W+\frac{1}{j w C_{d l}}\right)}{Y^{-1}(j w)^{-n_{1}}+\left(R_{c t}+W+\frac{1}{j w C_{d l}}\right)}\right]
$$

The circuit parameters are $n_{l}, R_{c t}, C_{d l}, R_{s}$ and $W$ which need to be estimated.

By comparing the experimental $Z_{t}$ values with the predictions from (A4) for various frequencies, the best set of parameters are obtained. Subsequently, the real and imaginary components of the impedance are calculated which yield Nyquist and Bode plots depicted in figure 7.

\section{References}

1. Conway B E 1999 Electrochemical supercapacitors: scientific fundamentals and technological applications (New York: Kluwer Academic/Plenum Publications)

2. Shukla A K, Arico A S and Antonucci V 2001 Renewable Sustainable Energy Rev. 5137

3. Lin C, Ritter J A and Papov B N 1998 J. Electrochem. Soc. 1454097

4. Zheng, J P and Jow T R 1995 J. Electrochem. Soc. 142 L6

5. Srinivasan V and Weidner J W $2000 \mathrm{~J}$. Electrochem. Soc. $\mathbf{1 4 7} 880$

6. Ji Yeong Lee, Kay Hyeok An, Jeong $\mathrm{Ku}$ Heo and Young Hee Lee 2003 J. Phys. Chem. B107 8812

7. Frackawiak E and Beguin F 2002 Carbon 401775

8. Niu C, Sichel E K, Hoch R, Moy D and Tennet H 1997 Appl. Phys. Lett. 701480

9. Sarangapani S, Tilak B V and Chen C P 1996 J. Electrochem. Soc. 1433791

10. Girija T C and Sangaranarayanan M V 2005 Indian J. Chem. A44 1395

11. Hideki Shirakawa 2001 Rev. Mod. Phys. 713

12. Sujit Kumar Mondal, Rajendra Prasad, K and Munichandraiah N 2005 Syn. Met. 148275

13. Virginia Ruiz, Alvaro Colina, Aranzazu Heras and Jesus Lopez-Palacios 2006 Polymer degradation and stability 913117

14. Pandey P C and Prakash R 1998 J. Electrochem. Soc. 1454103

15. Said Sadki, Philippe Schottland S, Nancy Brodie and Guillaume Sabouraud 2000 Chem. Soc. Rev. 29283

16. Bergaoui S, Haj Sard A, Roudesli S and Matoussi F 2006 Electrochim. Acta $\mathbf{5 1} 4309$

17. Rajesh, Bisht V, Takashima W and Kaneto K 2005 Reactive and Functional Polymers 6251

18. Steen Skaarup, Lasse Bay and Keld West 2007 Syn. Met. 157323

19. Vishnuvardhan T K, Kulkarni V R, Basavaraja C and Raghavendra S C 2006 Bull. Mater. Sci. 2977

20. Chen W and Wen T 2003 J. Power Sour. 117273

21. Vadivel Murugan A, Reddy M V, Guy Campet and Vijayamohanan K 2007 J. Electroanal. Chem. 603287

22. Girija T C and Sangaranarayanan M V 2006 Syn. Met. 156244

23. Evgenij Barsoukov and Ross Macdonald J (eds) 2005 Impedance spectroscopy: Theory, experiment, and applications (New York: Wiley-Interscience), Chapter 1, p. 7 